\title{
Oligarchie der Geistlichkeit. Funktionsweisen und Grenzen des Klientelismus im Kirchenstaat der Frühen Neuzeit
}

\author{
Annina Wachter \\ Kerngebiet: Neuzeit \\ eingereicht bei: Dr. Niels Grüne \\ eingereicht im: SoSe 2017 \\ Rubrik: SE-Arbeit
}

\begin{abstract}
An Oligarchy of the Clergy

The following seminar paper is about clientelism and networking in the Papal State of the Early Modern Age. It will examine the functions and limits of interconnectedness between the dignitaries of the Curia and especially the role of the cardinal nepot. It will be shown that clientelism was a central tool of the early modern micropolitics of the Papal State.
\end{abstract}

\section{Einleitung}

Der Kirchenstaat stellt ein umfangreiches Fallbeispiel für Patronagebeziehungen in der Frühen Neuzeit dar, wobei besonders der viel praktizierte Kardinalnepotimus der Päpste, ein „Sonderfall neuzeitlicher Mikropolitik“1, der seinen Höhepunkt im 15. bis 17. Jahrhundert erreichte, aufschlussreiche Erkenntnisse über die Machtstrukturen im Kirchenstaat liefert. ${ }^{2}$

Jens Ivo Engels, Die Geschichte der Korruption. Von der Frühen Neuzeit bis ins 20. Jahrhundert, Frankfurt a. M. 2014, S. 43.

2 Birgit Emich, Bürokratie und Nepotismus unter Paul V. (1605-1621). Studien zur frühneuzeitlichen Mikropolitik, Stuttgart 2001, S. 9. 
Patronage und Korruption in der Frühen Neuzeit weckten erst in der jüngeren Vergangenheit das Interesse der Historiker_innen. ${ }^{3}$ Dennoch ist der Forschungsstand umfangreich. Vor allem die Werke „Bürokratie und Nepotismus unter Paul V. (1605-1621)“ von Birgit Emich ${ }^{4}$ und „Die Geschichte der Korruption“ von Jens Ivo Engels ${ }^{5}$ behandeln die Thematik ausführlich, genauso wie die Forschungen zur Geschichte des Nepotismus von Wolfgang Reinhard (1972, 1979, 1984, 2005, 2009)6', Volker Reinhardt (2001, 2002, 2003, 2005)7, Nicole Reinhardt (2000, 2002) ${ }^{8}$ und Günther Wassilowsky (2005, 2010) ${ }^{9}$. Auch zur theoretischen Definition des Korruptionsbegriffes gibt es ausführliche Forschungen, unter anderem den Aufsatz "The Search for Definitions. The Vitality of Politics and the Issue of Corruption"von Michael Johnston ${ }^{10}$. Zur Geschichte des Papsttums bieten einige kirchengeschichtliche Werke einen guten Überblick, auch wenn dieses Feld der Literatur quellenkritisch gelesen werden sollte, da vor allem ältere Werke der Papstgeschichtsschreibung im Kern oft legitimatorischen Interessen dienten. ${ }^{11}$

3 Hillard von Thiessen, Korrupte Gesandte? Konkurrierende Normen in der Diplomatie der Frühen Neuzeit, in: Niels Grüne/Simona Slanička (Hrsg.), Korruption. Historische Annäherungen an eine Grundfigur politischer Kommunikation, Göttingen 2010, S. 205-220, hier S. 208.

4 Emich, Bürokratie und Nepotismus unter Paul V. (1605-1621).

5 Engels, Die Geschichte der Korruption.

$6 \quad$ Wolfgang Reinhard, Ämterhandel in Rom zwischen 1534 und 1621, in: Ilja Mieck (Hrsg.), Ämterhandel im Spätmittelalter und im 16. Jahrhundert. Referate eines internationalen Colloquiums in Berlin vom 1.-3. Mai 1980, Berlin 1984, S. 42-60; Wolfgang Reinhard, Freunde und Kreaturen. „Verflechtung” als Konzept zur Erforschung historischer Führungsgruppen. Römische Oligarchie um 1600, München 1979; Wolfgang Reinhard, Papa Pius. Prolegma zu einer Sozialgeschichte des Papsttums, in: Remigius Bäumer (Hrsg.), Von Konstanz nach Trient. Beiträge zur Geschichte der Kirche von den Reformkonzilien bis zum Tridentinum. Festgabe für August Franzen, München-Paderborn-Wien 1972, S. 261-300; Wolfgang Reinhard, Paul V. Borghese (1605-1621). Mikropolitische Papstgeschichte, Stuttgart 2009; Wolfgang Reinhard, Symbol und Performanz zwischen kurialer Mikropolitik und kosmischer Ordnung, in: Günther Wassilowsky/Hubert Wolf (Hrsg.), Werte und Symbole im frühneuzeitlichen Rom (Symbolische Kommunikation und gesellschaftliche Wertesysteme, Schriften des Sonderforschungsbereichs 496/11), Münster 2005, S. 37-50.

7 Volker Reinhardt, Kreise stören - Kreise schlagen. Perspektiven römischer Elitenforschung, in: Daniel Büchel/ Volker Reinhard (Hrsg.), Die Kreise der Nepoten. Neue Forschungen zu alten und neuen Eliten Roms in der frühen Neuzeit, Bern 2001, S. 11-30; Volker Reinhardt, Einführung: Nepotismus, Papstfinanz und römische Elitenverflechtung, in: Peter Burschel u. a. (Hrsg.), Historische Anstöße. Festschrift für Wolfgang Reinhard zum 65. Geburtstag am 10. April 2002, Berlin 2002, S. 173-178; Volker Reinhardt, Normenkonkurrenz an der neuzeitlichen Kurie, in: Günther Wassilowsky/Hubert Wolf (Hrsg.), Werte und Symbole im frühneuzeitlichen Rom (Symbolische Kommunikation und gesellschaftliche Wertesysteme, Schriften des Sonderforschungsbereichs 496/11), Münster 2005, S. 51-66; Volker Reinhardt, Rom in Italien - Gedanken zu einer vielschichtigen Thematik, in: Daniel Büchel/ Volker Reinhard (Hrsg.), Modell Rom? Der Kirchenstaat und Italien in der Frühen Neuzeit, Köln-Weimar-Wien 2003, S. 11-18.

8 Nicole Reinhardt, Macht und Ohnmacht der Verflechtung. Rom und Bologna unter Paul V. - Studien zur frühneuzeitlichen Mikropolitik im Kirchenstaat, Tübingen 2000; Nicole Reinhardt, "Verflechtung" - ein Blick zurück nach vorn, in: Peter Burschel u. a. (Hrsg.), Historische Anstöße. Festschrift für Wolfgang Reinhard zum 65. Geburtstag am 10. April 2002, Berlin 2002, S. 235-262.

9 Günther Wassilowsky, Die Konklavereform Gregors XV. (1621/22). Wertekonflikte, symbolische Inszenierung und Verfahrenswandel im posttridentinischen Papsttum (Päpste und Papsttum 38), Stuttgart 2010; Günther Wassilowsky, Vorsehung und Verflechtung. Theologie und Mikropolitik im Konklavezeremoniell Gregors XV. (1621/22), in: Günther Wassilowsky/Hubert Wolf (Hrsg.), Werte und Symbole im frühneuzeitlichen Rom (Symbolische Kommunikation und gesellschaftliche Wertesysteme, Schriften des Sonderforschungsbereichs 496/11), Münster 2005, S. 67-82; Günther Wassilowsky, Werte- und Verfahrenswandel bei den Papstwahlen in Mittelalter und Früher Neuzeit, in: Christoph Dartmann/Günther Wassilowsky/Thomas Weller (Hrsg.), Technik und Symbolik vormoderner Wahlverfahren, München 2010, S. 139-182.

10 Michael Johnston, The Search for Definitions. The Vitality of Politics and the Issue of Corruption, in: International Social Science Journal 48 (1996), S. 321-335.

11 Hubert Wolf, Symbolische Kommunikation am heiligen Hof des Papstes. Eine Einleitung, in: Günther Wassilowsky/ Hubert Wolf (Hrsg.), Werte und Symbole im frühneuzeitlichen Rom (Symbolische Kommunikation und gesellschaftliche Wertesystem. Schriften des Sonderforschungsbereichs 496/11), Münster 2005, S. 9-20, hier S. 11. 
Im Zuge dieser Arbeit werden die Fragen beantwortet, wie der Klientelismus im Kirchenstaat der Frühen Neuzeit funktionierte und welches Maß an Korruption in ihm als "normal" galt, bzw. ab welcher Ausprägung sie als verwerflich angesehen wurde. Welche Konsequenzen konnte Korruption nach sich ziehen? Drohte korrupten Amtsträgern eine rechtliche Bestrafung? Insbesondere wird auf die Rolle des Kardinalnepoten eingegangen, indem erforscht wird, welche Aufgaben ihm zukamen und wie sich sein Amt gestaltete. Als These wird einerseits angenommen, dass der Kardinalnepot für die eigentliche Verwaltung der päpstlichen Patronagebeziehungen zuständig war und andererseits bei Korruptionsvorwürfen als „Blitzableiter“ des Papstes Verwendung fand. Des Weiteren wird angenommen, dass korrupte Amtsträger im Kirchenstaat zwar durchaus mit rechtlichen Konsequenzen rechnen mussten, vor allem durch Konklavereformen und päpstliche Bullen, nicht jedoch der Papst selbst, da es in der Kirche keine Gewalt gab, die ihm übergeordnet war. ${ }^{12}$

\section{Korruption im historischen Kontext}

\subsection{Definition: Patronage und Klientelismus}

Korruption ist ein kontroverser Begriff, der in einer Vielzahl wissenschaftlicher Definitionsversuche beschrieben wurde. ${ }^{13}$ Nach den gesetzlichen und sozialen Standards versteht man darunter den Missbrauch einer öffentlichen Rolle oder Ressource für privaten Nutzen, also zum Beispiel die Verwendung eines politischen Amtes zum persönlichen Vorteil. ${ }^{14}$ Das Wort Korruption verfügt über negative Konnotationen wie Zerstörung, Zerfall oder Zersetzung ${ }^{15}$ und wird mit Ungleichheit und Legitimitätsverlust assoziiert. $^{16}$

Der Ausgangspunkt von Korruption kann eine sogenannte Patron-Klient-Beziehung sein. Dabei handelt es sich um eine „persönliche, dauerhafte, asymmetrische und reziproke Tauschbeziehung"17, gekennzeichnet durch einen Verschleierungsaspekt, was bedeutet, dass eine solche Beziehung rein sprachlich durch ihre "Semantik des gegenseitigen Wohlwollens"18 kaum von einer symmetrischen Freundschaft zu unterscheiden ist. Es erfolgt ein kontinuierlicher Gabentausch, motiviert dadurch, dass beide Akteure immer wieder in der Schuld des jeweils anderen stehen oder zu stehen glauben und sich eine gegenseitige Abhängigkeit durch das Gefühl entwickelt, dem anderen

12 Winfried Aymans/Klaus Mörsdorf, Kanonisches Recht, Bd. 2, Paderborn 1997, S. 205.

13 Niels Grüne, „Und sie wissen nicht, was es ist". Ansätze und Blickpunkte historischer Korruptionsforschung, in: Niels Grüne/Simona Slanička (Hrsg.), Korruption. Historische Annäherungen, Göttingen 2010, S. 11-34, hier S. 29.

14 Johnston, The Search for Definitions, S. 331.

15 Ernesto Garzón Valdés, Zur moralischen Bewertung von Korruption: Ein Vorschlag, in: Ulrich von Alemann (Hrsg.), Dimensionen politischer Korruption. Beiträge zum Stand der internationalen Forschung (Politische Vierteljahresschrift, Sonderheft 35), Wiesbaden 2005, S. 155-163, hier S. 155.

16 Jens Borchert, Einleitung. Von Berufskölnern, alten Römern und paradoxen Konsequenzen, in: Jens Borchert/ Sigrid Leitner/Klaus Stolz (Hrsg.), Politische Korruption (Jahrbuch für Europa- und Nordamerikastudien 3), Opladen 2000, S. 7-18, hier S. 9.

17 Guido O. Kirner, Politik, Patronage und Gabentausch. Zur Archäologie vormoderner Sozialbeziehungen in der Politik moderner Gesellschaften, in: Berliner Debatte Initial 14 (2003), Heft 4, S. 168-183, hier S. 170

18 Kirner, Politik, Patronage und Gabentausch, S. 171. 
persönlich verpflichtet zu sein. ${ }^{19}$ Mit der Annahme eines Geschenks wird bewusst die Verpflichtung eingegangen, sich bei einer folgenden Gelegenheit zu revanchieren ${ }^{20}$ und im Rahmen dieser Beziehung werden von beiden Seiten gewisse Leistungen erbracht, für die sie im Gegenzug Vorteile erhalten. ${ }^{21}$ Korruption verbindet demnach Pflichterfüllung mit Gewinn. ${ }^{22}$

Die Frage, was ein Geschenk eigentlich ist bzw. sein kann, ist komplex²3; grundsätzlich gilt, dass ein Geschenk als „eine Transaktion in einer besonderen rhetorischen Form“24 beschrieben werden kann. Die Darbietung eines Geschenkes für einen Amtsträger kann einerseits als bloßer Ausdruck von Ehrerbietung gewertet werden, andererseits als heimliche Zuwendung zum Zweck des Erreichens bestimmter Ziele, die auf legalem Wege nicht erreichbar wären.. ${ }^{25}$ Korruption ist daher ein Austauschprozess zwischen zwei oder mehreren Personen oder Gruppen, die zusammen auch Parteien bilden können. ${ }^{26}$

Typische Formen von Korruption sind Bestechung, was einen freiwilligen Tausch von Leistung und Gegenleistung zwischen zwei Akteuren bedeutet, bzw. Erpressung, gekennzeichnet durch die Unfreiwilligkeit des Tauschvorganges. Des Weiteren werden Unterschlagung bzw. Veruntreuung öffentlicher Mittel, Patronage und eine regelwidrige Bevorzugung von verwandten oder befreundeten Personen beim Zugang zu einem Öffentlichen Amt zur Korruption gezählt. ${ }^{27}$ Dazu muss gesagt werden, dass Bestechung und Erpressung auch Hand in Hand gehen können, denn in vielen Fällen werden Bestechungsgelder nicht gezahlt, um Vorteile zu erlangen, sondern um Nachteile zu vermeiden. ${ }^{28}$ Bestochen wurde außerdem seit jeher nicht nur mit Geld. ${ }^{29}$

\subsection{Der Korruptionsbegriff der Frühen Neuzeit}

Für den Begriff Korruption gab es in der Geschichte eine Reihe von Konnotationen. Manchmal wurde er als Klage über die Dekadenz der Zeit oder den moralischen Verfall der ganzen Politik verwendet, während er in anderen Zeiten auf spezifische Gefahren hinwies, die mit Bestechung, Simonie oder Ämterkauf verbunden waren. ${ }^{30}$ Korruption kann jedenfalls nicht als objektiver Tatbestand gesehen werden, denn wel-

19 Kirner, Politik, Patronage und Gabentausch, S. 171.

20 Ruth Zimmerling, Politische Korruption. Begrifflich-theoretische Einordnung, in: Ulrich von Alemann (Hrsg.), Dimensionen politischer Korruption. Beiträge zum Stand der internationalen Forschung (Politische Vierteljahresschrift, Sonderheft 35), Wiesbaden 2005, S. 77-90, hier S. 81.

21 Christian Höffling, Korruption als soziale Beziehung, Opladen 2002, S. 26

22 Karl Wilhelm Rennstich, Korruption und Religion, München 2005, S. 13.

23 Felicity Heal, The Power of Gifts. Gift-Exchange in Early Modern England, Oxford 2014, S. 6.

24 Valentin Groebner, Gefährliche Geschenke. Ritual, Politik und Sprache der Korruption in der Eidgenossenschaft im späten Mittelalter und am Beginn der Neuzeit, Konstanz 2000, S. 13.

25 Thiessen, Korrupte Gesandte?, S. 209.

26 Konstantin Pozdnyakov, "Korruption“. Kritische Rekonstruktion der Ursachen, Folgen und Therapien einer scheinbaren Wachstumsbranche, Norderstedt 2009, S. 9.

27 Rupert F. J. Pritzl/Friedrich Schneider, Korruption, Linz 1997, S. 7-9.

28 Paul Noack, Korruption. Die andere Seite der Macht, München 1987, S. 41.

29 Alfred Sturminger, Die Korruption in der Weltgeschichte, München 1982, S. 14.

30 Bruce Buchan/Lisa Hill, An Intellectual History of Political Corruption, London 2014, S. 171. 
che Verhaltensweisen als korrupt gelten, hängt von der jeweiligen Gesellschaft ab. ${ }^{31}$ Verändert sich die Struktur der Gesellschaft und des Staates, verändert sich auch der Klientelismus. ${ }^{32}$ Die Auffassung darüber, was korrupt ist, kann also räumlich, zeitlich oder kulturell durchaus variieren, ${ }^{33}$ da jedes Zeitalter über seine eigenen Konflikte und Dilemmata verfügt. ${ }^{34}$

In der ständischen Gesellschaft war Patronage ein wichtiger Bestandteil, der zentrale Funktionen in der Strukturierung und Organisation der Herrschaft einnahm. Sie war Kulturform und soziale Institution und als solche nahm sie gerade auch im Staatsbildungsprozess zentrale Aufgaben wahr. ${ }^{35}$ Durch „Verflechtung”, die das "Ergebnis und [die] Basis sozialer Interaktion“36 darstellt, funktionierten die zentralen Beziehungen innerhalb des Netzwerkes, nämlich Freundschaft, Verwandtschaft, Nachbarschaft und Patronage, also verschiedene Formen informaler Organisation, welche dadurch definiert wird, dass die Arbeitsleistung von Menschen „nicht nur von objektiven Arbeitsbedingungen und formalen Regelungen, sondern ganz wesentlich auch von sozialen Faktoren geprägt ist." ${ }^{137}$

Grundsätzlich kann Korruption auch für die Frühe Neuzeit als eine „missbräuchliche Inanspruchnahme eines öffentlichen Amtes für private Zwecke"38 definiert werden, obwohl es bis ins 17. Jahrhundert für den Begriff zwei mögliche Deutungen gab: Einerseits meinte er „eine individuelle, Bereicherung oder Vorteilsnahme darstellende Normverletzung zu Lasten des Gemeinguts, die zu bestrafen war", andererseits verstand man sie „in einem die gesamte Gesellschaft erfassenden Sinn als Verfall und Auflösung”. ${ }^{9}$

\section{Korruption im Kirchenstaat}

\subsection{System, Machtstrukturen und Funktionsweisen}

Im Europa der Frühen Neuzeit gab es drei grundlegende Herrschaftsformen: die Monarchie, die Aristokratie und die monarchia mixta, die aus aristokratischen und monarchischen Elementen zusammengesetzt war..$^{40}$ Der Kirchenstaat hingegen war eine

31 Petra Stykow, Mésalliance à trois. Politische Korruption als Beziehungsphänomen, in: Harald Bluhm/Karsten Fischer (Hrsg.), Sichtbarkeit und Unsichtbarkeit der Macht. Theorien politischer Korruption, Baden-Baden 2002, S. 87-113, hier S. 89.

32 Sharon Kettering, The Historical Development of Political Clientelism, in: Journal of Interdisciplinary History 18 (1988), S. 419-447, hier S. 420.

33 Pritzl/Schneider, Korruption, S. 5.

34 William J. Chambliss, Kritische Kriminologie und die Theorie der Korruption, in: Christian Fleck/Helmut Kuzmics (Hrsg.), Korruption, Wien 1982, S. 3-16, hier S. 10.

35 Heiko Droste, Patronage in der Frühen Neuzeit. Institution und Kulturform, in: Zeitschrift für Historische Forschung 30 (2003), S. 555-590, hier S. 557.

36 Reinhardt, ,Verflechtung" - ein Blick zurück nach vorn, S. 236.

37 Birgit Emich, Die Formalisierung des Informellen: Der Fall Rom, in: Reinhard Butz/Jan Hirschbiegel (Hrsg.), Informelle Strukturen bei Hof (Dresdner Gespräche III zur Theorie des Hofes), Berlin 2009, S. 149-156, hier S. $149-150$

38 Pritzl/Schneider, Korruption, S. 5.

39 Thiessen, Korrupte Gesandte?, S. 210

40 Luise Schorn-Schütte, Geschichte Europas in der Frühen Neuzeit. Studienhandbuch 1500-1789, Paderborn 2009, S. 98-99. 
zölibatäre Wahlmonarchie, in der theoretisch bei jedem Herrscherwechsel eine neue Familie die Macht erlangen konnte ${ }^{41}$ - ein instabiles System, das beim Tod eines Papstes keinen Erben vorsah. Stattdessen sollte in der Zeit zwischen dem Tod eines Papstes und der Wahl seines Nachfolgers, der Sedisvakanz, durch den Kardinalschatzmeister das Kardinalskollegium einberufen werden, um in der Isolierung des Konklaves einen neuen Papst zu wählen. ${ }^{42}$

Der Papst hatte zwei Ämter inne: Zum einen war er das Oberhaupt der katholischen Kirche, zum anderen war er weltlicher Fürst des Kirchenstaates ${ }^{43}$ und verfügte über immense Ressourcen, denn die Kirche war reich. ${ }^{44}$ Kirchenämter brachten massive Einkünfte und eine politische Bedeutung mit sich, denn oft kamen ihnen weltliche Aufgaben und Rechte zu. Als Oberhaupt des Kirchenstaates verfügte der Papst über weltliche Einkünfte, eine Armee und ein Netz an Diplomaten über ganz Europa. ${ }^{45}$ Auswärtige Adelstitel sicherten die Papstfamilien international ab, und darüber hinaus profitierte der Kirchenstaat von erfolgreichen Beziehungen zu europäischen Mächten. Von Seiten der katholischen europäischen Großmächte wurde oft versucht, die Papstwahl zu beeinflussen. ${ }^{46}$

Das Amt des Pontifex stand also in der lebendigen Mitte Europas ${ }^{47}$ und brachte einerseits eine gewaltige weltliche Macht mit sich, verfügte andererseits aber nur über eine geringe Stabilität. Oft folgte auf einen Pontifex einer seiner Gegner, sodass die mikropolitischen Arrangements unvermittelt durcheinandergewirbelt wurden. ${ }^{48}$ Diese Mikropolitik, also der planmäßige Einsatz personaler Netzwerke zu politischen Zwecken ${ }^{49}$, war ein wesentlicher Bestandteil frühneuzeitlicher Politik. ${ }^{50}$ Bei jedem Pontifikatswechsel wurden die Karten neu gemischt: Änderungen im politischen und administrativen Bereich waren zwangsläufig die Folge und es ergaben sich stets neue, wechselhafte Konstellationen. ${ }^{51}$

Auf diese Weise bekam ein Kandidat aber auch alle paar Jahre die Chance, selbst in das höchste Amt der Kirche aufzusteigen.52 Bei Pontifikaten, die als „zu lang“ wahrgenommen wurden, kam es durchaus zu Äußerungen des Missfallens vonseiten der außenstehenden Anwärter, weil sich ihnen für eine lange Zeitspanne nicht die Chance des

41 Birgit Emich u. a., Stand und Perspektiven der Patronageforschung. Zugleich eine Antwort auf Heiko Droste, in: Zeitschrift für Historische Forschung 32 (2005), S. 233-265, hier S. 239.

42 Antonino Lopes, Die Päpste. Ihr Leben im Laufe der 2000-jährigen Geschichte, Rom 2005, S. 119.

43 Lopes, Die Päpste, S. 119.

44 Germain Bazin, Paläste des Glaubens. Eine Geschichte der Klöster vom 15. bis zum Ende des 18. Jahrhunderts, München 1980, S. 24.

45 Engels, Geschichte der Korruption, S. 43.

46 Ebd.

47 Reinhardt, Rom in Italien, S. 11.

48 Engels, Geschichte der Korruption, S. 44.

49 Guido Metzler, Französische Mikropolitik in Rom unter Papst Paul V. Borghese (1605-1621), Heidelberg 2008 , S. 8.

50 Metzler, Französische Mikropolitik in Rom, S. 159

51 Alfred A. Strnad, Die Päpste der Früh- und Hochrenaissance, in: Martin Greschat (Hrsg.), Das Papsttum II. Vom Großen Abendländischen Schisma bis zur Gegenwart (Gestalten der Kirchengeschichte 12), Stuttgart 1985, S. 39-52, hier S. 44 
Aufstieges bot. Dieses Zusammenspiel von Stabilität und Mobilität war ein spezifisch römisches Problem. ${ }^{53}$

Neben seinen Ämtern als geistliches und weltliches Oberhaupt hatte der Papst noch eine dritte Funktion inne, nämlich die eines Familienoberhauptes. In der oft kurzen Zeit zwischen der Wahl eines Pontifex und dessen Tod hatte seine Familie die einmalige Gelegenheit, in der römischen Gesellschaft ganz nach oben aufzusteigen. ${ }^{54}$ Während des Aufstieges solcher neureicher Papstangehöriger erfolgte außerdem oft gleichzeitig ein Abstieg alteingesessener Familien. ${ }^{55}$

Diese große soziale Mobilität schuf im Kirchenstaat den idealen Nährboden für Klientelismus, ${ }^{56}$ ein System gekennzeichnet durch den Einsatz von Patronage. ${ }^{57}$ „Wer Karriere machen wollte, trug die Soutane" ${ }^{58}$, denn Klientelismus ermöglichte im Kirchenstaat wie auch in vielen anderen politischen Systemen gesellschaftlichen Aufstieg. 59

\subsection{Simonie und Klientelismus}

Simonie bedeutet Korruption in der Kirche und wird kirchenrechtlich als unerlaubter Handel mit spirituellen Dingen definiert. ${ }^{60}$ Sie bezeichnet den „Kauf des eigentlich Nichtkäuflichen"61 und "stellt den Gegenpol zur Heiligkeit und göttlich gewollten Unentgeltlichkeit der Gnadengabe des Heiligen Geistes dar" "62. Dadurch förderte sie oft ungeeignete Kandidaten, die mittels Dienstleistungen, Zahlungen und Versprechungen in der Kirche aufstiegen. ${ }^{63}$

Die Doppelrolle des Papstes als geistliches und weltliches Oberhaupt führte zu einer starken Säkularisierung des Papsttums, ${ }^{64}$ sodass sich die römische Kurie in Gestalt des Pontifex und der Kardinäle kaum von einem italienischen Fürstenhof unterschied. ${ }^{65} \mathrm{Ge}-$ handelt wurde mit Besitzungen, Gnaden, Ämtern, Pfründen und geistlichen Würden. ${ }^{66}$

Schon der englische Philosoph, Theologe und Kirchenreformer John Wyclif (1330-1384) sah die Simonie als degenerierte Patronage ${ }^{67}$ und erläuterte, die Einflussnahme von Verwandten bei der Stellenbesetzung führe dazu, dass geeignete

53 Reinhard, Freunde und Kreaturen, S. 46.

54 Engels, Geschichte der Korruption, S. 44-45.

55 Reinhardt, Macht und Ohnmacht der Verflechtung, Tübingen 2000, S. 36

56 Emich u. a., Stand und Perspektiven der Patronageforschung, S. 239.

57 Metzler, Französische Mikropolitik in Rom, S. 8.

58 Bazin, Paläste des Glaubens, S. 24.

59 Engels, Geschichte der Korruption, S. 78.

60 Gunda Steffen-Gaus, Gute Patrone als Korrektoren der Simonie. Das Korruptionsmodell in John Wyclifs „De Simonia", in: Niels Grüne/Simona Slanička (Hrsg.), Korruption. Historische Annäherungen, Göttingen 2010, S. 79-98, hier S. 79.

61 Pritzl/Schneider, Korruption, S. 17.

62 Steffen-Gaus, Gute Patrone als Korrektoren der Simonie, S. 79.

63 Ebd

64 Birgit Emich, Territoriale Integration in der Frühen Neuzeit. Ferrara und der Kirchenstaat, Köln-Weimar-Wien 2005, S. 607 .

65 Georg Denzler, Das Papsttum. Geschichte und Gegenwart, München 2009³, S. 67.

66 Reinhard, Ämterhandel in Rom, S. 46

67 Steffen-Gaus, Gute Patrone als Korrektoren der Simonie, S. 94. 
Personen übergangen würden. ${ }^{68}$ Die Konsequenz von Korruption sei, dass Talent verfälscht würde. ${ }^{69}$ Insbesondere beflecke die Simonie "die Weihen der spirituellen Ämter, vom Pfarrpriester über Ordensgeistliche, Bischöfe und Kardinäle bis hin zum Papst." ${ }^{170}$

Dennoch wurden Simonie und Klientelismus in der Öffentlichkeit weniger verschleiert, als man annehmen könnte. Patron-Klient-Beziehungen wurden im Papstzeremoniell sogar öffentlich zur Schau gestellt, z. B. indem kostbare Stoffe für Zeremonien von edlen Spendern gestiftet wurden. ${ }^{11}$ Das Zeremoniell bot eine Möglichkeit, Freundschaft, Landsmannschaft und Patronage als Strukturelement der sozialen Ordnung darzustellen - und damit auch als legitime Norm. ${ }^{72}$ Die Kreaturen des Papstes nahmen oft sein Wappen als Teilschild in ihr Siegelwappen auf, ${ }^{73}$ und eine Auszeichnung, die besonders gerne vom Papst an seine Klienten vergeben wurde, war die Goldene Rose. ${ }^{74}$

Der Papst konnte seinen Klienten auf verschiedene Arten das Leben erleichtern. Trotz vorliegender kanonischer Hindernisse konnte er eine Eheschließung erlauben und die gesetzliche Begrenzung der Mitgift aufheben, und auch die Legitimierung von Bastarden lag in seiner Macht. Er konnte das gesetzliche Mindestalter für den Erhalt von Pfründen übergehen und unzulängliche Adelsnachweise anerkennen, genauso wie Befreiungen vom Fasten- und Abstinenzgebot erteilen. Bei Verbrechen konnte der Papst die Täter begnadigen. ${ }^{75}$

\subsection{Nepotismus}

Der päpstliche Nepotismus war im 16. und 17. Jahrhundert „ein Sonderfall neuzeitlicher Mikropolitik" und funktionierte nur auf dem Fundament eines eher untypischen politischen Systems. Einerseits gab es im Kirchenstaat, wie schon erwähnt, keine dynastische Erbfolge, andererseits verwoben sich in Rom lokale und europäische Interessen. $^{76}$

Der Kardinalnepot gilt als Schlüsselfigur des päpstlichen Herrschaftssystems. ${ }^{77}$ Das Amt wurde durch Papst Paul III. etabliert, ab 1538 regelmäßig besetzt und erst durch Papst Innozenz XII. im Jahr 1692 wieder abgeschafft; der Kardinalnepot war meist ein Neffe oder ein ähnlich naher Verwandter des Papstes, der kurz nach dessen eigener Wahl die Kardinalsweihe empfing. Er wurde vom Papst mit Gütern und Würden entlohnt für die Aufgabe, dessen Klienten und Freunde für ihre Loyalität mit Ämtern, Geld und Gna-

\footnotetext{
68 Steffen-Gaus, Gute Patrone als Korrektoren der Simonie, S. 98.

69 Paolo Mauro, Why worry about Corruption?, Washington 1997, S. 6.

70 Steffen-Gaus, Gute Patrone als Korrektoren der Simonie, S. 79.

71 Birgit Emich, Besitz ergreifen von der Kirche. Normen und Normkonflikte beim Zeremoniell des päpstlichen Possesso, in: Günther Wassilowsky/Hubert Wolf (Hrsg.), Werte und Symbole im frühneuzeitlichen Rom (Symbolische Kommunikation und gesellschaftliche Wertesysteme, Schriften des Sonderforschungsbereichs 496/11), Münster 2005, S. 83-100, hier S. 87.

72 Emich, Besitz ergreifen von der Kirche, S. 98.

73 Reinhard, Papa Pius, S. 292.

74 Ebd., S. 290.

75 Reinhard, Paul V. Borghese (1605-1621), S. 46.

76 Engels, Geschichte der Korruption, S. 43.

77 Emich, Bürokratie und Nepotismus unter Paul V. (1605-1621), S. 9.
} 
denakten zu würdigen. Er saß wie eine Spinne im Netz der Beziehungen ${ }^{78}$ und hatte von Amts wegen auf Privatinteressen und Eigennutz zu achten. ${ }^{79}$ Seine Aufgabe war die Transformierung der Meinungen, Stimmungen, Willensäußerungen und Gefühle seines Onkels in konkrete Handlungsweisen. ${ }^{80}$

Dieser Neffe bekam eine Stellung, die mit einem Günstlingsminister zu vergleichen ist, war Kardinal, Staatssekretär und Oberhaupt einer Behörde, die sich unter anderem mit der Verwaltung der Patronageressourcen des Papstes beschäftigte. Er kümmerte sich darum, dass die Papstfamilie Titel, Einkünfte und Gefolgschaft erhielt. Auch die Verbindungen zu anderen Höfen gehörten dazu. ${ }^{81}$ Sein Amt war ein Phänomen, das auf augenscheinliche Weise die „Formalisierung des Informellen" 82 im Kirchenstaat verdeutlicht.

Oft hatte der Kardinalnepot auch eine Funktion als Präfekt von Verwaltungskongregationen bzw. als Leiter verschiedener Gremien inne ${ }^{83}$, oder er war Korrespondent und Koordinator in militärischen Angelegenheiten. ${ }^{84}$ Päpste setzten überwiegend Verwandte als militärische Führer und als Leiter der unsicheren Regionen ein, sodass neu eroberte Gebiete des Kirchenstaates zu selbstständigen Herrschaften für Neffen und Söhne umgewandelt wurden - was sowohl im Kardinalskolleg als auch in den betreffenden Gebieten auf Widerstand stieß und die Beziehungen zu anderen italienischen Staaten erschwerte. ${ }^{85}$

Auch die Kunstpatronage fiel in die Zuständigkeit des Nepoten. ${ }^{86}$ Einige der bedeutendsten Antikensammlungen Roms entstanden mit dem Beginn der Amtszeit eines neuen Papstes und dem Machtantritt einer Aufsteigerfamilie. ${ }^{87}$ Seit Sixtus IV. griffen die Päpste mithilfe ihrer Nepoten auch aktiv in die Stadtplanung Roms ein, indem sie neue Verbindungsstraßen anlegen und prächtige Kardinalspaläste errichten ließen. ${ }^{88}$ Auch das Amt des Erzpriesters von Sankt Peter bekleidete meist ein Neffe. ${ }^{89}$

Insgesamt hatte der Kardinalnepot mithin drei wichtige Funktionen inne: Erstens führte er als Behördenchef die amtliche Korrespondenz des Staatssekretariats und der Kongregationen, zweitens die Patronagekorrespondenz und drittens die päpstliche

78 Emich, Bürokratie und Nepotismus unter Paul V. (1605-1621), S. 10.

79 Ebd.

80 Christian Wieland, Fürsten, Freunde, Diplomaten. Die römisch-florentinischen Beziehungen unter Paul V. (16051621), Köln 2004, S. 150.

81 Engels, Geschichte der Korruption, S. 44-45.

82 Birgit Emich, Die Formalisierung des Informellen. Ein Beitrag zur Verwaltungsgeschichte der Frühen Neuzeit, in: Peter Eich (Hrsg.), Der Wiederkehrende Leviathan. Staatlichkeit und Staatswerdung in Spätantike und Früher Neuzeit, Heidelberg 2011, S. 81-96, hier S. 93.

83 Emich, Bürokratie und Nepotismus unter Paul V. (1605-621), S. 214.

84 Ebd., S. 239

85 Bernhard Schimmelpfennig, Das Papsttum. Von der Antike bis zur Renaissance, Darmstadt 1988³, S. 271-272.

86 Arne Karsten, Künstler und Kardinäle. Vom Mäzenatentum römischer Kardinalnepoten im 17. Jahrhundert, Köln 2003, S. 9

87 Petra Thomas, Wissen ist Macht? Kataloge von Antikensammlungen als Ausdruck von sozialer Selbstbehauptung und Wissenschaftlichkeit, in: Daniel Büchel/Nolker Reinhardt (Hrsg.), Modell Rom? Der Kirchenstaat und Italien in der Frühen Neuzeit, Köln-Weimar-Wien 2003, S. 185-202, hier S. 185. 
Privatkorrespondenz. ${ }^{90}$ Er arbeitete als Klientelchef, Behördenleiter und Vertreter privater Interessen. ${ }^{91}$ Zwar waren die römischen Funktionsträger von Amts wegen verpflichtet, die Anordnungen des Nepoten als Leitlinien der päpstlichen Politik auf Allgemeinwohlorientierung und Überparteilichkeit zu überprüfen und gegebenenfalls Einspruch zu erheben, als Klienten wussten sie aber, dass sie auf Widerspruch lieber verzichten sollten..$^{92}$

Die päpstliche Administration war also ein Teil des nepotistischen Systems ${ }^{93}$, welches als Alternativform zur direkten Erblichkeit versuchte, den erreichten sozialen Status einer Familie abzusichern und materiellen Reichtum für künftige Generationen zu erhalten. ${ }^{94}$ Kardinäle wurden in sehr jungem Alter ernannt - oft schon als Kinder - und arbeiteten darauf hin, sich politische Beziehungen und Prestige zu sichern. ${ }^{95}$ Die Neffen wurden für bestimmte Laufbahnen ausgewählt, um im besten Fall das Erbe des Onkels anzutreten; zudem wurden einige von ihnen für eine weltliche Karriere ausgewählt, um im Zuge geschickter Heiratspolitik in alte, etablierte Adelsgeschlechter einzuheiraten. ${ }^{96}$

Das Ziel des Nepotismus war es also, trotz des Zölibates Kontinuität und Erblichkeit zu gewährleisten, sodass sich im Idealfall eine Form von informellem Neffenerbrecht etablierte. ${ }^{97}$ Außerdem erfüllte er die zu jener Zeit geläufige moralische Norm um das Gebot der Pietas ${ }^{98}$ (in diesem Zusammenhang: Pflichtgefühl, Elternliebe, Dankbarkeit), welches besagte, dass die sozial höhergestellten Verwandten für die bedürftigeren aufkommen sollten. ${ }^{99}$ Die Förderung von Verwandten und Landsleuten galt als eine selbstverständliche Pflicht. ${ }^{100}$

Wie stark der Nepotismus etabliert war, zeigt sich an der Tatsache, dass vier Familien insgesamt neunmal den Papstthron bestiegen. ${ }^{101}$ Bei Papstwahlen konkurrierten stets dieselben Clans, unter anderem die der Orsini und der Colonna ${ }^{102}$, und in der Regel „stammten allein aus dem Kirchenstaat mehr Kardinäle als aus allen Ländern [...] zusammen.."103 Rom entwickelte einen unheilvollen Ruf als „Sammelplatz aller Übel“104, wo sich schlechte Ratgeber, Verführer und Neider tummelten; der Kirchenstaat funktionierte „als Oligarchie römischer Kardinalsfamilien"105.

90 Emich, Bürokratie und Nepotismus unter Paul V. (1605-1621), S. 396

91 Ebd., S. 401.

92 Ebd.

93 Ebd., S. 11.

94 Ingo Stader, Herrschaft durch Verflechtung. Perugia unter Paul V. (1605-1621). Studien zur frühneuzeitlichen Mikropolitik im Kirchenstaat (Beiträge zur Kirchen- und Kulturgeschichte), Frankfurt a. M. 1997, S. 191

95 Alberto Melloni, Das Konklave. Die Papstwahl in Geschichte und Gegenwart, Freiburg 2002, S. 52.

96 Stader, Herrschaft durch Verflechtung, S. 191.

97 Reinhard, Freunde und Kreaturen, S. 49.

98 Reinhardt, Macht und Ohnmacht der Verflechtung, S. 34

99 Stader, Herrschaft durch Verflechtung, S. 191.

100 Reinhard, Symbol und Performanz, S. 38.

101 Schimmelpfennig, Das Papsttum, S. 272.

102 Heiner Boberski, Der nächste Papst. Die geheimnisvolle Welt des Konklave, Salzburg-Wien 1999, S. 101.

103 Boberski, Der nächste Papst, S. 78.

104 Erwin Iserloh, Die Päpste im Zeitalter der Reformation und des Konzils von Trient, in: Martin Greschat (Hrsg.), Das Papsttum II. Vom Großen Abendländischen Schisma bis zur Gegenwart (Gestalten der Kirchengeschichte 12), Stuttgart 1985, S. 53-78, hier S. 53.

105 Engels, Geschichte der Korruption, S. 64. 
In der älteren Literatur findet man oft die Deutung, die politische Renaissance "mit ihrem skrupellosen Getriebe"106 hätte hier auch vom Papsttum Besitz ergriffen und Nepotismus und Familienpolitik hätten auf diesem Hintergrund eine unheilvolle Rolle gespielt. ${ }^{107}$ Die positive Seite der Verwandtenbegünstigung der Päpste wird jedoch häufig übersehen: Das Heranziehen von Familienangehörigen und Landsleuten trug nämlich dazu bei, dem Regierungssystem eines Papstes größere Effizienz zu verleihen, da ihm als gewählter Herrscher mitunter eine nähere Bindung an Land und Leute fehlte. Von den eigenen Verwandten konnte er Loyalität erwarten, da sie durch ihre eigenen Interessen an der Festigung seiner Herrschaft interessiert sein mussten. ${ }^{108}$ "Einen Patron konnte man wechseln, einen Onkel nicht." ${ }^{109}$ Ehemalige Kardinalnepoten wurden für gewöhnlich „aus dem Zentrum der Macht an den Rand der Bedeutungs- und Einflusslosigkeit" ${ }^{110}$ geschoben.

\section{Vorgehen gegen Korruption}

"Gnadengeschenke werden ohne Zeitaufschub eingefordert, und es ist offenkundig, daß sie über Gebühr erpreßt werden. Die Kirchenämter werden nicht mehr dem übertragen, der es verdient, sondern dem, der am meisten dafür bietet."111

Dieses Zitat stammt aus dem Brief eines kurmainzischen Beamten an Kardinal Enea Silvio Piccolomini (1405-1464) aus dem Jahr 1457 - Piccolomini begann ein Jahr später sein Pontifikat als Pius II. - und zeigt einerseits, wie gängig Simonie und Nepotismus zu diesem Zeitpunkt bereits waren; andererseits wird deutlich, dass der Ämterhandel durchaus thematisiert und verurteilt wurde. Korruptionsdebatten reflektieren Modernisierungsprozesse ${ }^{112}$, haben unabhängig von ihrem Wahrheitsgehalt aber auch das Potential, politische Systeme zu destabilisieren. ${ }^{113}$

Seit dem Pontifikat von Sixtus IV. (1471-1484) wuchsen die Steuererhebungen, während die Käuflichkeit wichtiger Ämter immer offensichtlicher wurde. ${ }^{114}$ Wie wurde nun gegen die Korruption im Kirchenstaat vorgegangen? Den Anfang machte Julius II. (1503-1513), indem er mit seiner Bulle Cum tam divino (1506) eine durch Simonie zu-

106 Michael Seidlmayer, Geschichte Italiens, Stuttgart 1962, S. 289

107 Josef Gelmi, Das Renaissance-Papsttum. Humanismus und Renaissance, in: Bruno Moser (Hrsg.), Das Papsttum. Epochen und Gestalten, München 1983, S. 108-116, hier S. 108.

108 Strnad, Die Päpste der Früh- und Hochrenaissance, S. 44.

109 Reinhard, Symbol und Performanz, S. 38.

110 Tobias Mörschel, Von der Vergänglichkeit der Macht. Der Kardinalnepot Pietro Aldobrandini (1571-1621), in: Arne Karsten (Hrsg.), Jagd nach dem roten Hut. Kardinalskarrieren im barocken Rom, Göttingen 2004, S. 88-104, hier S. 94

111 Günter Stemberger, 2000 Jahre Christentum. Illustrierte Kirchengeschichte in Farbe, Stuttgart 1983, S. 422.

112 Jens Ivo Engels, Politische Korruption und Modernisierungsprozesse. Thesen zur Signifikanz der Korruptionskommunikation in der westlichen Moderne, in: Niels Grüne/Simona Slanička (Hrsg.), Korruption. Historische Annäherungen, Göttingen 2010, S. 35-54, hier S. 35.

113 Andreas Fahrmeir, Investitionen in politische Karrieren? Politische Karrieren als Investition? Tendenzen und Probleme historischer Korruptionsforschung, in: Jens Ivo Engels (Hrsg.), Geld - Geschenke - Politik. Korruption im neuzeitlichen Europa, München 2009, S. 67-90, hier S. 71.

114 Gaston Castella, Papstgeschichte. Von Petrus bis zur Wiedererneuerung der Katholischen Kirche, Bd. 1, Zürich 1966, S. 422 
stande gekommene Papstwahl für ungültig erklärte, was Paul IV. (1555-1559) mit Cum secundum (1558) bekräftigte.

Im Jahr 1572 wurde durch Papst Gregor XIII. (1572-1585) eine Zeremonialkongregation ins Leben gerufen, die Congregatio super reformatione ceremoniali, deren Aufgabe es sein sollte, die päpstlichen Zeremonienbücher, welche die Abläufe an Papsthof und Kurie regelten, grundlegend zu reformieren. Allerdings lässt sich die Existenz dieser Zeremonialkongregation nur bis 1580 nachweisen, was vermuten lässt, dass die beabsichtigte Reform des Zeremoniells spätestens zu diesem Zeitpunkt endgültig im Sande verlaufen war. ${ }^{115}$

Sixtus V. (1585-1590) begrenzte mit der Bulle Postquam verus (1586) die Zahl der zur Wahl zugelassenen Kardinäle auf siebzig, um Parteibildungen im Konsistorium zu beschränken, und verbot 1590 Verhandlungen über die kommende Wahl zwischen den Kardinälen. ${ }^{116}$ Ab 1591 wurde die eigenständige Congregatione per la riforma del Conclave institutionalisiert, die ein Jahr später auch einen ersten Bullenentwurf hervorbrachte, welcher jedoch wieder zurückgezogen wurde. ${ }^{117}$

In den Jahren 1621/22 wurde schließlich durch Papst Gregor XV. (1621-1623) eine Konklavereform erlassen. Die Konstitution Aeterni Patris Filius und das dazugehörige Caeremoniale in Electione Summi Romani Pontificis observandum führten eine umfangreiche Veränderung der konkreten Abläufe des Konklaves herbei und zeigten überdies einen "fundamentalen Paradigmenwechsel“118 der Papstgeschichte an. Die wichtigste Neuerung war die Abschaffung der Adorationswahl, eines öffentlich stattfindenden Wahlvorganges, bei dem ein Kandidat praktisch nur zwei Drittel der Stimmen benötigte, um zu gewinnen, und stattdessen die Einführung der sogenannten Skrutinalwahl, einer geheimen Abstimmung mit Hilfe von Stimmzetteln. ${ }^{119}$ Von nun an wurde das Konklave nicht mehr in der Paulinischen, sondern in der Sixtinischen Kapelle abgehalten, wo bei der Stimmabgabe jeder der Kardinäle unter Michelangelos Fresco des Jüngsten Gerichtes die bis heute gebräuchliche Eidesformel abzulegen hatte: „Christus den Herrn, der mein Richter sein wird, nehme ich zum Zeugen, dass ich denjenigen wähle, den ich nach Gottes Willen wählen muss." ${ }^{\prime 20}$ Das innere Gewissen sollte bei der Papstwahl nun den Ausschlag geben, nicht die äußere Verflechtung. ${ }^{121}$ Die Einführung dieses freien, geordneten und geheimen Verfahrens zur Wahl eines Papstes sollte nepotistischen und nationalen Klientelverbänden entgegenwirken. ${ }^{122}$ Wichtig war im Zuge der Einführung der neuen Skrutinalwahl auch die symbolische Inszenierung des Geheimen mit der Zelebration von Beschriften, Falten und Versiegeln des Stimmzettels als Symbol für die Ordnung und Regelhaftigkeit des Vorganges. ${ }^{123}$

115 Wassilowsky, Die Konklavereform Gregors XV. (1621/22), S. 154-155.

116 Melloni, Das Konklave, S. 55-56.

117 Wassilowsky, Die Konklavereform Gregors XV. (1621/22), S. 157-158.

118 Wassilowsky, Werte- und Verfahrenswandel bei den Papstwahlen, S. 140.

119 Ebd., S. 176-177.

120 Ebd., S. 178.

121 Ebd., S. 240.

122 Wassilowsky, Die Konklavereform Gregors XV. (1621/22), S. 238.

123 Ebd., S. 340. 
Obwohl die Konklavereform Gregors XV. als erste schriftliche Normierung der genauen Verfahrensformen zur Papstwahl in der Geschichte ${ }^{124}$ sicher nicht sofort ein Umdenken bei allen Teilnehmern bewirken konnte und die Ergebnisse des Konklave auch weiterhin von gegenseitigen Abhängigkeiten und Patronage gekennzeichnet waren, wurde das neue, geheime Verfahren zumindest seit der Wahl Urbans VIII. (1523-1644) eingehalten. Damit war er der erste Papst, der durch eine geheime Abstimmung sein Amt erlangte. ${ }^{125}$ Die Praxis der Adorationswahl war definitiv verbannt. ${ }^{126}$

Die Konklavereform von 1621/22 war somit ein großer Schritt im Vorgehen gegen die Korruption im Konklave. Welche Konsequenzen allerdings das korrupte Verhalten eines bereits gewählten Papstes nach sich zog, ist schwer zu sagen. Ein Papst setzte als Bischof von Rom das von Christus an Petrus übertragene Amt fort und hatte daher nicht nur einen Ehrenvorrang vor den anderen Bischöfen, sondern war vielmehr das Haupt des Bischofskollegiums und konnte de facto nicht abgesetzt werden. ${ }^{127}$ Der Papst verfügte über die sogenannte Primatialgewalt, also die "höchste, volle, unmittelbare und universale ordentliche Gewalt"128, die er frei ausüben konnte, und über die sogenannte Höchstgewalt (potestas suprema). Das bedeutet, dass es in der Kirche keine Gewalt gab, die ihm rechtlich übergeordnet war. ${ }^{129}$

Hier stellt sich die Frage, was mit ungeeigneten Päpsten geschehen sollte. Mittelalterliche Kirchenrechtler wie Huguccio waren der Auffassung, ein Pontifex würde automatisch sein Amt verlieren, wenn er offenkundig vom Glauben abgekommen sei ( $a$ fide devius). Dies sollte gegebenenfalls durch ein Konzil oder das Kardinalskonsistorium festgestellt werden. Allerdings war diese Idee nicht vereinbar mit der neuzeitlichen Entwicklung der Lehre von Papst und Kirche, ${ }^{130}$ denn der Pontifex war als oberster Richter der Kirche selbst keinem kirchlichen Gericht unterworfen (prima sedes a nemine indicatur). Die Amtsgewalt des Papstes umfasste Exekutive, Legislative und auch Judikative - Urteile des Papstes waren daher unanfechtbar. ${ }^{131}$

Ein Verfahren zur Absetzung eines Papstes war nicht vorgesehen und praktisch unmöglich. Die einzigen Beispiele für Amtsenthebungen seit dem Spätmittelalter geschahen im Zuge des Konzils von Konstanz und betrafen Gegenpapst Johannes XXIII. (1415) und Benedikt XIII. (1417). Abgesehen von diesen beiden Fällen bestand (und besteht) die einzige Möglichkeit zur Enthebung eines Papstes von seinem Amt in einem freiwilligen Verzicht, was in der Kirchengeschichte nur sehr selten vorkam und meist durch äußeren Druck geschah. ${ }^{132}$

\footnotetext{
124 Wassilowsky, Die Konklavereform Gregors XV. (1621/22), S. 339.

125 Wassilowsky, Werte- und Verfahrenswandel bei den Papstwahlen, S. 179.

126 Wassilowsky, Die Konklavereform Gregors XV. (1621/22), S. 341.

127 Aymans/Mörsdorf, Kanonisches Recht, S. 203.

128 Ebd., S. 205.

129 Ebd.

130 Ebd.

131 Ebd., S. 206.

132 Lopes, Die Päpste, S. 74.
} 
Es gab folglich keine Strafen für das korrupte Verhalten eines neuzeitlichen Papstes, da kirchenrechtlich keine Instanz über ihm stand. In vielen Fällen lässt sich vermuten, dass bei Korruptionsvorwürfen ein Kardinalnepot als „Blitzableiter" verwendet und des Amtes enthoben wurde, bis das Amt im Jahr 1692 durch Papst Innozenz XII. (1691-1700) endgültig abgeschafft wurde. Die politischen Funktionen des Kardinalnepoten waren bereits ab 1644 seit Innozenz X. (1644-1655) allmählich auf den Kardinalstaatssekretär übergegangen. ${ }^{133}$

\section{Historische Einordnung}

Als negative Beispiele für sogenannte "Renaissance-Päpste" gelten neben Paul V. (1605-1621) vor allem Sixtus IV. (1471-1484), der nicht weniger als fünf seiner Neffen zu Kardinälen ernannte ${ }^{134}$, Innozenz VIII. (1484-1492), Alexander VI. (1492-1503) und Julius II. (1503-1513). Sie im Speziellen sollen ihr Amt zu persönlichen Machtzwecken missbraucht ${ }^{135}$, Ämter ver- und gekauft und ihre nächsten Angehörigen in wichtige Ämter eingesetzt und mit Fürstentümern und Ländereien des Kirchenstaates bedacht haben. Dabei seien ihnen alle Mittel recht gewesen, von Korruption bis Gewalt ${ }^{136}$, und somit entsprachen in dieser Epoche die meisten Päpste dem damals üblichen Bild eines italienischen Renaissancefürsten. ${ }^{137}$

Vor allem Alexander VI., der oft verteufelte und verrissene Borgia-Papst, galt lange Zeit als der Inbegriff von Skrupellosigkeit, Korruption und des kompletten Mangels an moralischem Bewusstsein ${ }^{138}$ und als „teuflischer als Satan selbst"139. Die Assoziationen, die mit seinem Namen verbunden werden, sind Nepotismus, Verschwendungssucht, Korruption und Arroganz. ${ }^{140}$ Bekannt ist Alexander VI., der das Amt des Papstes durch Bestechung erlangt haben soll ${ }^{141}$, vor allem dafür, dass er 1498 den Dominikaner Girolamo Savonarola (1452-1498) hinrichten ließ, nachdem dieser die Korruption der römischen Kurie angeprangert hatte. ${ }^{142}$ Den Nepotismus trieb der Borgia-Papst auf die Spitze, was sich schon daran erkennen lässt, dass er selbst nie zum Priester geweiht, sondern von seinem Onkel Papst Kalixtus III. (1455-1458) zum Kardinal ernannt worden war. Der Kardinal Cesare Borgia (1475-1507) war außerdem nicht nur Alexanders ältester leiblicher Sohn, sondern auch Großneffe des Papstes Kalixtus III. und Cousin der Kardinäle Juan (1446-1503) und Pedro de Borja Lanzol de Romani (1472-1511). ${ }^{143}$

133 Birgit Emich, Verstaatlichung des Nepotismus. Der Heimfall Ferraras an den Kirchenstaat, in: Daniel Büchel/Volker Reinhardt (Hrsg.), Modell Rom? Der Kirchenstaat und Italien in der Frühen Neuzeit, Köln-Weimar-Wien 2003, S. 223-240, hier S. 233.

134 Boberski, Der nächste Papst, S. 100.

135 Ulrike Peters, Kirchengeschichte. Ein Schnellkurs, Köln 2008, S. 82.

136 Peters, Kirchengeschichte, S. 82

137 Schimmelpfennig, Das Papsttum, S. 269.

138 Lopes, Die Päpste, S. 79.

139 Marion Hermann-Röttgen, Die Borgia. Geschichte und Geschichten, in: Elisabeth Schraut (Hrsg.), Die Renaissancefamilie Borgia. Geschichte und Legende, Sigmaringen 1992, S. 15-23, hier S. 15.

140 Lopes, Die Päpste, S. 79.

141 Denzler, Das Papsttum, S. 69.

142 P. Miguel Batllori, Die Renaissancepolitik Alexander VI.: Rom, Italien, Spanien, Europa, in: Elisabeth Schraut (Hrsg.), Die Renaissancefamilie Borgia. Geschichte und Legende, Sigmaringen 1992, S. 24-27, hier S. 26-27.

143 Sarah Bradford, Cesare Borgia. Ein Leben in der Renaissance, Hamburg 1979, S. 77. 
Mittlerweile hat sich das Bild von Alexander VI. allerdings deutlich zu seinen Gunsten gewandelt. Seine Politik gilt heute weitgehend als geschickt ${ }^{144}$, er selbst als „pünktlich und tüchtig"145 und als "ausgezeichneter Jurist"146 und, dem Zeitgeist entsprechend, als großer Förderer der Kunst ${ }^{147}$, wenn er auch „den sittlichen Tiefpunkt des Papsttums verkörperte"148. Immerhin soll er auch vor Giftmord nicht zurückgeschreckt sein. ${ }^{149}$ Sein Ziel sei es gewesen, mit dem Kirchenstaat einen Staat zu formen, in dem geistliche und weltliche Macht vollkommen verschmolzen wären, um die führende Stellung der römischen Kirche in der Welt der neu entstehenden europäischen Staaten behaupten zu können. ${ }^{150}$

Auch Innozenz VIII. soll Intrigen und Bestechung für seine Wahl zum Papst genutzt haben ${ }^{151}$, doch was heute als Skandal bezeichnet werden würde, wurde von der damaligen Gesellschaft allgemein toleriert. ${ }^{152}$ Der Nepotismus war integraler Bestandteil päpstlicher Herrschaftsorganisation in der Frühen Neuzeit ${ }^{153}$ und wurde als deutlich weniger skandalös wahrgenommen, als es heute der Fall wäre. Wie eingangs erwähnt, hängt es von der jeweiligen Gesellschaft ab, welche Verhaltensweisen als korrupt gelten, ${ }^{154}$ und Patronage war ein wichtiger Bestandteil der ständischen Gesellschaft. ${ }^{155}$

In den meisten Patronagesystemen herrschte außerdem durchaus ein Bewusstsein dafür, dass die eigenen Klienten nur bis zu einem gewissen Grade bevorzugt werden durften, denn anderenfalls konnte es schnell zu einem Vorwurf der Parteilichkeit kommen. Auch die Papstfamilie durfte ihre eigene Gefolgschaft nicht maßlos bevorzugen, sondern musste die Möglichkeit von Ressourcen und Ämtern auch für alle anderen grundsätzlich offenhalten. Die Kosten der Patronage durften außerdem nicht zu hoch erscheinen, denn sonst drohte der Vorwurf der Korruption. ${ }^{156}$

144 Strnad, Die Päpste der Früh- und Hochrenaissance, S. 46.

145 Hans Conrad Zander, Der Heilige und der Sünder, in: Bruno Moser (Hrsg.), Das Papsttum. Epochen und Gestalten, München 1983, S. 117-132, hier S. 120.

146 Zander, Der Heilige und der Sünder, S. 119

147 Massimo Grillandi, Lucretia Borgia, Düsseldorf 1991, S. 10.

148 Boberski, Der nächste Papst, S. 101.

149 Reinhardt, Normenkonkurrenz an der neuzeitlichen Kurie, S. 51.

150 Paolo Prodi, „Plures in papa considerantur personae distinctae“. Zur Entwicklung der Papsttums in der Neuzeit, in: Günther Wassilowsky/Hubert Wolf (Hrsg.), Werte und Symbole im frühneuzeitlichen Rom (Symbolische Kommunikation und gesellschaftliche Wertesysteme, Schriften des Sonderforschungsbereichs 496/11), Münster 2005, S. 21-36, hier S. 25.

151 Castella, Papstgeschichte, S. 433.

152 Lopes, Die Päpste, S. 78.

153 Arne Karsten, „Nepotismum discussurus“ - Die Kosakenaffäre 1662 und ihre Auswirkungen auf die NepotismusDiskussion an der Kurie, in: Peter Burschel u. a. (Hrsg.), Historische Anstöße. Festschrift für Wolfgang Reinhard zum 65. Geburtstag am 10. April 2002, Berlin 2002, S. 263-290, hier S. 269.

156 Engels, Geschichte der Korruption, S. 77. 


\section{Schluss}

Wenn von "Korruption" gesprochen wird, ist damit generell der Missbrauch einer öffentlichen Rolle oder Ressource für privaten Nutzen gemeint, ${ }^{157}$ oft gewährleistet durch eine Patron-Klient-Beziehung bzw. Patronage. ${ }^{158}$ Letztere war ein wichtiger Bestandteil in der ständischen Gesellschaft, da sie zentrale Funktionen in der Strukturierung und Organisation der Herrschaft einnahm. ${ }^{159}$

Im Zuge dieser Arbeit wurde die Frage beantwortet, wie der Klientelismus im Kirchenstaat funktionierte, nämlich durch die zentralen Formen informaler Organisation: Freundschaft, Verwandtschaft, Nachbarschaft und Patronage. ${ }^{160}$ Keinesfalls handelte es sich bei den Zuständen im Kirchenstaat um "mafiose Korruption in einer abstrusen Theaterwelt" "161; vielmehr nutzte der Papst sein Netzwerk von Familienangehörigen und Landsleuten, da er von ihnen die größte Loyalität erwarten und seinem Regierungssystem größere Effizienz verleihen konnte. ${ }^{162}$ Bei der Geschichte des Papsttums handelte es sich nicht um eine Abfolge einzelner Herrscherpersönlichkeiten, sondern um eine von sozialen und wirtschaftlichen Faktoren geprägte Oligarchie, die der eigentliche Träger der Kontinuität war. ${ }^{163}$ Außerdem gab es sehr wohl das Bewusstsein, die eigenen Klienten nicht grenzenlos zu bevorzugen, da der Vorwurf der Parteilichkeit vermieden werden und die Möglichkeit der Gefolgschaft auch für alle anderen grundsätzlich offen bleiben sollte. ${ }^{164}$

Der wichtigste Amtsträger war in diesem System der Kardinalnepot ${ }^{165}$, der dank seiner geistlichen Weihen auf die Geldmittel der Kirche zugreifen konnte ${ }^{166}$ und sich um die Verwaltung der Patronageressourcen des Papstes kümmerte. Damit kann die These dieser Arbeit als bestätigt angesehen werden: Die Aufgabe des Kardinalnepoten war die praktische Verwaltung der päpstlichen Patronagebeziehungen. ${ }^{167}$ Allerdings darf man sich die politische Kultur des Klientelismus nicht als das Administrieren und Regieren einzelner Nepoten in Spitzenpositionen vorstellen ${ }^{168}$, sondern vielmehr als die Vernetzung der regierenden Papstfamilie mit ihren Klienten. Den einzelnen Angehörigen wurden Funktionen zugewiesen, um die Papstfamilie abzusichern. ${ }^{169}$

Die Korruption im Kirchenstaat wurde als Symptom des moralischen Verfalls und der Degenerierung gedeutet und auch öffentlich kritisiert: ${ }^{170}$ Dass informelle Netzwerke in

\footnotetext{
157 Johnston, The Search for Definitions, S. 331.

158 Kirner, Politik, Patronage und Gabentausch, S. 170.

159 Droste, Patronage in der Frühen Neuzeit, S. 557.

160 Reinhardt, ,'Verflechtung" - ein Blick zurück nach vorn, S. 236.

161 Reinhard, Symbol und Performanz, S. 49.

162 Strnad, Die Päpste der Früh- und Hochrenaissance, S. 44.

163 Reinhard, Freunde und Kreaturen, S. 45.

164 Engels, Geschichte der Korruption, S. 77.

165 Emich, Bürokratie und Nepotismus unter Paul V. (1605-1621), S. 9.

166 Emich, Territoriale Integration, S. 44.

167 Engels, Geschichte der Korruption, S. 44-45.

168 Reinhardt, Einführung, S. 176.

169 Christian Wieland, Florentiner in Rom. Vom Wandel von "Loyalität” und "Vertrauen” im Italien des 16. und 17. Jahrhunderts, in: Birgit Emich/Christian Wieland (Hrsg.), Kulturgeschichte des Papsttums in der Frühen Neuzeit, Berlin 2013, S. 147-188, hier S. 170.

170 Buchan/Hill, An Intellectual History of Political Corruption, S. 99.
} 
der wechselhaften politischen Kultur der päpstlichen Wahlmonarchie eine große Rolle spielten, wird durch die massive zeitgenössische Kritik an der römischen Verflechtung umso mehr bestätigt. ${ }^{171}$

Konsequenzen dieser Korruption waren mehrere päpstliche Bullen zur Eindämmung unerlaubter Absprachen bei der Papstwahl sowie die Konklavereform von Gregor XV. in den Jahren 1621/22. ${ }^{172}$ Für den amtierenden Papst selbst zog korruptes Verhalten allerdings keine Bestrafung nach sich, da es in der Kirche keine rechtliche Gewalt gab, die über ihm stand. Der Papst war oberster Richter der Kirche und daher selbst keinem kirchlichen Gericht unterworfen; seine Urteile waren unanfechtbar und ein Verfahren zu seiner Absetzung war weder vorgesehen noch möglich. ${ }^{173}$ Dass ein Kardinalnepot bei Korruptionsvorwürfen als "Blitzableiter" des Papstes verwendet wurde, kann vermutet, aber nicht zweifelsfrei bestätigt werden; das Ende der Macht eines Kardinalnepoten kam meist mit dem Tod "seines" Papstes - oder wenig später. ${ }^{174}$

\section{Literatur}

Aymans, Winfried/Mörsdorf, Klaus, Kanonisches Recht, Bd. 2, Paderborn 1997.

Batllori, P. Miguel, Die Renaissancepolitik Alexander VI.: Rom, Italien, Spanien, Europa, in: Elisabeth Schraut (Hrsg.), Die Renaissancefamilie Borgia. Geschichte und Legende, Sigmaringen 1992, S. 24-27.

Bazin, Germain, Paläste des Glaubens. Eine Geschichte der Klöster vom 15. bis zum Ende des 18. Jahrhunderts, München 1980.

Borchert, Jens, Einleitung. Von Berufskölnern, alten Römern und paradoxen Konsequenzen, in: Jens Borchert/Sigrid Leitner/Klaus Stolz (Hrsg.), Politische Korruption (Jahrbuch für Europa- und Nordamerikastudien 3), Opladen 2000, S. 7-18.

Boberski, Heiner, Der nächste Papst. Die geheimnisvolle Welt des Konklave, SalzburgWien 1999.

Bradford, Sarah, Cesare Borgia. Ein Leben in der Renaissance, Hamburg 1979.

Buchan, Bruce/Hill, Lisa, An Intellectual History of Political Corruption, London 2014.

Castella, Gaston, Papstgeschichte. Von Petrus bis zur Wiedererneuerung der Katholischen Kirche, Bd. 1, Zürich 1966.

Chambliss, William J., Kritische Kriminologie und die Theorie der Korruption, in: Christian Fleck/Helmut Kuzmics (Hrsg.), Korruption, Wien 1982, S. 3-16.

Denzler, Georg, Das Papsttum. Geschichte und Gegenwart, München 2009.

171 Günther Wassilowsky, Vorsehung und Verflechtung. Theologie und Mikropolitik im Konklavezeremoniell Gregors XV. (1621/22), in: Günther Wassilowsky/Hubert Wolf (Hrsg.), Werte und Symbole im frühneuzeitlichen Rom (Symbolische Kommunikation und gesellschaftliche Wertesysteme, Schriften des Sonderforschungsbereichs 496/11), Münster 2005, S. 67-82, hier S. 72.

172 Wassilowsky, Werte- und Verfahrenswandel, S. 178.

173 Aymans/Mörsdorf, Kanonisches Recht, S. 206.

174 Mörschel, Von der Vergänglichkeit der Macht, S. 94. 
Droste, Heiko, Patronage in der Frühen Neuzeit. Institution und Kulturform, in: Zeitschrift für Historische Forschung 30 (2003), S. 555-590.

Emich, Birgit, Besitz ergreifen von der Kirche. Normen und Normkonflikte beim Zeremoniell des päpstlichen Possesso, in: Günther Wassilowsky/Hubert Wolf (Hrsg.), Werte und Symbole im frühneuzeitlichen Rom (Symbolische Kommunikation und gesellschaftliche Wertesysteme, Schriften des Sonderforschungsbereichs 496/11), Münster 2005, S. 83-100.

Emich, Birgit, Bürokratie und Nepotismus unter Paul V. (1605-1621). Studien zur frühneuzeitlichen Mikropolitik, Stuttgart 2001.

Emich, Birgit, Die Formalisierung des Informellen: Der Fall Rom, in: Reinhard Butz/Jan Hirschbiegel (Hrsg.), Informelle Strukturen bei Hof (Dresdner Gespräche III zur Theorie des Hofes), Berlin 2009, S. 149-156.

Emich, Birgit, Die Formalisierung des Informellen. Ein Beitrag zur Verwaltungsgeschichte der Frühen Neuzeit, in: Peter Eich (Hrsg.), Der Wiederkehrende Leviathan. Staatlichkeit und Staatswerdung in Spätantike und Früher Neuzeit, Heidelberg 2011, S. 81-96.

Emich, Birgit, Territoriale Integration in der Frühen Neuzeit. Ferrara und der Kirchenstaat, Köln-Weimar-Wien 2005.

Emich, Birgit, Verstaatlichung des Nepotismus: Der Heimfall Ferraras an den Kirchenstaat, in: Daniel Büchel/Nolker Reinhard (Hrsg.), Modell Rom? Der Kirchenstaat und Italien in der Frühen Neuzeit, Köln-Weimar-Wien 2003, S. 223-240.

Emich, Birgit u. a., Stand und Perspektiven der Patronageforschung. Zugleich eine Antwort auf Heiko Droste, in: Zeitschrift für Historische Forschung 32 (2005), S. 233-265.

Engels, Jens Ivo, Die Geschichte der Korruption. Von der Frühen Neuzeit bis ins 20. Jahrhundert, Frankfurt a. M. 2014.

Engels, Jens Ivo, Politische Korruption und Modernisierungsprozesse. Thesen zur Signifikanz der Korruptionskommunikation in der westlichen Moderne, in: Niels Grüne/Simona Slanička (Hrsg.), Korruption. Historische Annäherungen, Göttingen 2010, S. 35-54.

Fahrmeir, Andreas, Investitionen in politische Karrieren? Politische Karrieren als Investition? Tendenzen und Probleme historischer Korruptionsforschung, in: Jens Ivo Engels (Hrsg.), Geld - Geschenke - Politik. Korruption im neuzeitlichen Europa, München 2009, S. 67-90.

Garzón Valdés, Ernesto, Zur moralischen Bewertung von Korruption: ein Vorschlag, in: Ulrich von Alemann (Hrsg.), Dimensionen politischer Korruption. Beiträge zum Stand der internationalen Forschung (Politische Vierteljahresschrift, Sonderheft 35), Wiesbaden 2005, S. 155-163.

Gelmi, Josef, Das Renaissance-Papsttum. Humanismus und Renaissance, in: Bruno Moser (Hrsg.), Das Papsttum. Epochen und Gestalten, München 1983, S. 108-116. 
Grillandi, Massimo, Lucretia Borgia, Düsseldorf 1991.

Groebner, Valentin, Gefährliche Geschenke. Ritual, Politik und Sprache der Korruption in der Eidgenossenschaft im späten Mittelalter und am Beginn der Neuzeit, Konstanz 2000.

Grüne, Niels, „Und sie wissen nicht, was es ist". Ansätze und Blickpunkte historischer Korruptionsforschung, in: Niels Grüne/Simona Slanička (Hrsg.), Korruption. Historische Annäherungen, Göttingen 2010, S. 11-34.

Heal, Felicity, The Power of Gifts. Gift-Exchange in Early Modern England, Oxford 2014. Hermann-Röttgen, Marion, Die Borgia. Geschichte und Geschichten, in: Elisabeth Schraut (Hrsg.), Die Renaissancefamilie Borgia. Geschichte und Legende, Sigmaringen 1992, S. 15-23.

Höffling, Christian, Korruption als soziale Beziehung, Opladen 2002.

Iserloh, Erwin, Die Päpste im Zeitalter der Reformation und des Konzils von Trient, in: Martin Greschat (Hrsg.), Das Papsttum II. Vom Großen Abendländischen Schisma bis zur Gegenwart (Gestalten der Kirchengeschichte 12), Stuttgart 1985, S. 53-78.

Johnston, Michael, The Search for Definitions. The Vitality of Politics and the Issue of Corruption, in: International Social Science Journal 48 (1996), S. 321-335.

Karsten, Arne, Künstler und Kardinäle. Vom Mäzenatentum römischer Kardinalnepoten im 17. Jahrhundert, Köln 2003.

Karsten, Arne, "Nepotismum discussurus" - Die Kosakenaffäre 1662 und ihre Auswirkungen auf die Nepotismus-Diskussion an der Kurie, in: Peter Burschel u. a. (Hrsg.), Historische Anstöße. Festschrift für Wolfgang Reinhard zum 65. Geburtstag am 10. April 2002, Berlin 2002, S. 263-290.

Kettering, Sharon, The Historical Development of Political Clientelism, in: Journal of Interdisciplinary History 18 (1988), S. 419-447.

Kirner, Guido O., Politik, Patronage und Gabentausch. Zur Archäologie vormoderner Sozialbeziehungen in der Politik moderner Gesellschaften, in: Berliner Debatte Initial 14 (2003), Heft 4, S. 168-183.

Lopes, Antonino, Die Päpste. Ihr Leben im Laufe der 2000-jährigen Geschichte, Rom 2005.

Mauro, Paolo, Why worry about Corruption?, Washington 1997.

Melloni, Alberto, Das Konklave. Die Papstwahl in Geschichte und Gegenwart, Freiburg 2002

Metzler, Guido, Französische Mikropolitik in Rom unter Papst Paul V. Borghese (16051621), Heidelberg 2008. 
Mörschel, Tobias, Von der Vergänglichkeit der Macht. Der Kardinalnepot Pietro Aldobrandini (1571-1621), in: Arne Karsten (Hrsg.), Jagd nach dem roten Hut. Kardinalskarrieren im barocken Rom, Göttingen 2004, S. 88-104.

Noack, Paul, Korruption. Die andere Seite der Macht, München 1987.

Peters, Ulrike, Kirchengeschichte. Ein Schnellkurs, Köln 2008.

Pozdnyakov, Konstantin, "Korruption“. Kritische Rekonstruktion der Ursachen, Folgen und Therapien einer scheinbaren Wachstumsbranche, Norderstedt 2009.

Pritzl, Rupert F. J./Schneider, Friedrich, Korruption, Linz 1997.

Prodi, Paolo, „Plures in papa considerantur personae distinctae“. Zur Entwicklung der Papsttums in der Neuzeit, in: Günther Wassilowsky/Hubert Wolf (Hrsg.), Werte und Symbole im frühneuzeitlichen Rom (Symbolische Kommunikation und gesellschaftliche Wertesysteme, Schriften des Sonderforschungsbereichs 496/11), Münster 2005, S. $21-36$.

Reinhardt, Nicole, Macht und Ohnmacht der Verflechtung. Rom und Bologna unter Paul V. - Studien zur frühneuzeitlichen Mikropolitik im Kirchenstaat, Tübingen 2000.

Reinhardt, Nicole, "Verflechtung” - ein Blick zurück nach vorn, in: Peter Burschel u. a. (Hrsg.), Historische Anstöße. Festschrift für Wolfgang Reinhard zum 65. Geburtstag am 10. April 2002, Berlin 2002, S. 235-262.

Reinhardt, Volker, Einführung: Nepotismus, Papstfinanz und römische Elitenverflechtung, in: Peter Burschel u. a. (Hrsg.), Historische Anstöße. Festschrift für Wolfgang Reinhard zum 65. Geburtstag am 10. April 2002, Berlin 2002, S. 173-178.

Reinhardt, Volker, Kreise stören - Kreise schlagen. Perspektiven römischer Elitenforschung, in: Daniel Büchel/Nolker Reinhard (Hrsg.), Die Kreise der Nepoten. Neue Forschungen zu alten und neuen Eliten Roms in der frühen Neuzeit, Bern 2001, S. 11-30.

Reinhardt, Volker, Normenkonkurrenz an der neuzeitlichen Kurie, in: Günther Wassilowsky/Hubert Wolf (Hrsg.), Werte und Symbole im frühneuzeitlichen Rom (Symbolische Kommunikation und gesellschaftliche Wertesysteme, Schriften des Sonderforschungsbereichs 496/11), Münster 2005, S. 51-66.

Reinhardt, Volker, Rom in Italien - Gedanken zu einer vielschichtigen Thematik, in: Daniel Büchel/Nolker Reinhard (Hrsg.), Modell Rom? Der Kirchenstaat und Italien in der Frühen Neuzeit, Köln-Weimar-Wien 2003, S. 11-18.

Reinhard, Wolfgang, Ämterhandel in Rom zwischen 1534 und 1621, in: Ilja Mieck (Hrsg.), Ämterhandel im Spätmittelalter und im 16. Jahrhundert. Referate eines internationalen Colloquiums in Berlin vom 1.-3. Mai 1980, Berlin 1984, S. 42-60.

Reinhard, Wolfgang, Freunde und Kreaturen. "Verflechtung" als Konzept zur Erforschung historischer Führungsgruppen. Römische Oligarchie um 1600, München 1979. 
Reinhard, Wolfgang, Papa Pius. Prolegma zu einer Sozialgeschichte des Papsttums, in: Remigius Bäumer (Hrsg.), Von Konstanz nach Trient. Beiträge zur Geschichte der Kirche von den Reformkonzilien bis zum Tridentinum. Festgabe für August Franzen, München-Paderborn-Wien 1972, S. 261-300.

Reinhard, Wolfgang, Paul V. Borghese (1605-1621). Mikropolitische Papstgeschichte, Stuttgart 2009.

Reinhard, Wolfgang, Symbol und Performanz zwischen kurialer Mikropolitik und kosmischer Ordnung, in: Günther Wassilowsky/Hubert Wolf (Hrsg.), Werte und Symbole im frühneuzeitlichen Rom (Symbolische Kommunikation und gesellschaftliche Wertesysteme, Schriften des Sonderforschungsbereichs 496/11), Münster 2005, S. 37-50.

Rennstich, Karl Wilhelm, Korruption und Religion, München 2005.

Schimmelpfennig, Bernhard, Das Papsttum. Von der Antike bis zur Renaissance, Darmstadt 1983.

Seidlmayer, Michael, Geschichte Italiens, Stuttgart 1962.

Schorn-Schütte, Luise, Geschichte Europas in der Frühen Neuzeit. Studienhandbuch 1500-1789, Paderborn 2009.

Stader, Ingo, Herrschaft durch Verflechtung. Perugia unter Paul V. (1605-1621). Studien zur frühneuzeitlichen Mikropolitik im Kirchenstaat (Beiträge zur Kirchen- und Kulturgeschichte), Frankfurt a. M. 1997.

Steffen-Gaus, Gunda, Gute Patrone als Korrektoren der Simonie. Das Korruptionsmodell in John Wyclifs „De Simonia”, in: Niels Grüne/Simona Slanička (Hrsg.), Korruption. Historische Annäherungen, Göttingen 2010, S. 79-98.

Stemberger, Günter, 2000 Jahre Christentum. Illustrierte Kirchengeschichte in Farbe, Stuttgart 1983.

Strnad, Alfred A., Die Päpste der Früh- und Hochrenaissance, in: Martin Greschat (Hrsg.), Das Papsttum II. Vom Großen Abendländischen Schisma bis zur Gegenwart (Gestalten der Kirchengeschichte 12), Stuttgart 1985, S. 39-52.

Sturminger, Alfred, Die Korruption in der Weltgeschichte, München 1982.

Stykow, Petra, Mésalliance à trois. Politische Korruption als Beziehungsphänomen, in: Harald Bluhm/Karsten Fischer (Hrsg.), Sichtbarkeit und Unsichtbarkeit der Macht. Theorien politischer Korruption, Baden-Baden 2002, S. 87-113.

Thiessen, Hillard von, Korrupte Gesandte? Konkurrierende Normen in der Diplomatie der Frühen Neuzeit, in: Niels Grüne/Simona Slanicka (Hrsg.), Korruption. Historische Annäherungen an eine Grundfigur politischer Kommunikation, Göttingen 2010, S. 205-220. 
Thomas, Petra, Wissen ist Macht? Kataloge von Antikensammlungen als Ausdruck von sozialer Selbstbehauptung und Wissenschaftlichkeit, in: Daniel Büchel/Volker Reinhardt (Hrsg.), Modell Rom? Der Kirchenstaat und Italien in der Frühen Neuzeit, KölnWeimar-Wien 2003, S. 185-202.

Wassilowsky, Günther, Die Konklavereform Gregors XV. (1621/22). Wertekonflikte, symbolische Inszenierung und Verfahrenswandel im posttridentinischen Papsttum (Päpste und Papsttum 38), Stuttgart 2010.

Wassilowsky, Günther, Vorsehung und Verflechtung. Theologie und Mikropolitik im Konklavezeremoniell Gregors XV. (1621/22), in: Günther Wassilowsky/Hubert Wolf (Hrsg.), Werte und Symbole im frühneuzeitlichen Rom (Symbolische Kommunikation und gesellschaftliche Wertesysteme, Schriften des Sonderforschungsbereichs 496/11), Münster 2005, S. 67-82.

Wassilowsky, Günther, Werte- und Verfahrenswandel bei den Papstwahlen in Mittelalter und Früher Neuzeit, in: Christoph Dartmann/Günther Wassilowsky/Thomas Weller (Hrsg.), Technik und Symbolik vormoderner Wahlverfahren, München 2010, S. 139-182.

Wieland, Christian, Florentiner in Rom. Vom Wandel von „Loyalität” und „Vertrauen” im Italien des 16. und 17. Jahrhunderts, in: Birgit Emich/Christian Wieland (Hrsg.), Kulturgeschichte des Papsttums in der Frühen Neuzeit, Berlin 2013, S. 147-188.

Wieland, Christian, Fürsten, Freunde, Diplomaten. Die römisch-florentinischen Beziehungen unter Paul V. (1605-1621), Köln 2004.

Wolf, Hubert, Symbolische Kommunikation am heiligen Hof des Papstes. Eine Einleitung, in: Günther Wassilowsky/Hubert Wolf (Hrsg.), Werte und Symbole im frühneuzeitlichen Rom (Symbolische Kommunikation und gesellschaftliche Wertesysteme, Schriften des Sonderforschungsbereichs 496/11), Münster 2005, S. 9-20.

Zander, Hans Conrad, Der Heilige und der Sünder, in: Bruno Moser (Hrsg.), Das Papsttum. Epochen und Gestalten, München 1983, S. 117-132.

Zimmerling, Ruth, Politische Korruption. Begrifflich-theoretische Einordnung, in: UIrich von Alemann (Hrsg.), Dimensionen politischer Korruption. Beiträge zum Stand der internationalen Forschung (Politische Vierteljahresschrift, Sonderheft 35), Wiesbaden 2005, S. 77-90.

Annina Wachter ist Studentin der Geschichte (Master) an der Universität Innsbruck. Annina.Wachter@student.uibk.ac.at 


\section{Zitation dieses Beitrages}

Annina.Wachter, Oligarchie der Geistlichkeit. Funktionsweisen und Grenzen des Klientelismus im Kirchenstaat der Frühen Neuzeit, in: historia.scribere 10 (2018), S. 267-289, [http://historia.scribere.at], eingesehen 19.6.2018 (=aktuelles Datum).

(C) Creative Commons Licences 3.0 Österreich unter Wahrung der Urheberrechte der Autorlnnen. 
